\title{
Study on the statistical model of the Relationship Between Job Planning and Undergraduate Students' Employment
}

\author{
Xiaomei Qi \\ Dongying Vocational College, Dongying, China \\ xiaomei_qi21@yeah.net
}

Keywords:career planning; employability; factor analysis; correlation analysis; regression analysis

\begin{abstract}
In recent years, the continued declining of college students' employment rate has been a big problem for most universities, and the only way out of this problem is to strengthen college students' career planning education. In this study, by using factor analysis and extracting four factors of career planning: the implementing and acting ability, thinking and expressing ability, career theory and career attitude, analyses on the relationship between each factor and graduates' employability are conducted. Then the correlations have been found. By using the regression analysis for a further study, the regression equation of the graduate employability and career planning is established to realize the prediction of the graduate employability. The research process is rational and scientific, and the result is objective. Thus this study can provide a certain basis for the career planning education in colleges.
\end{abstract}

\section{Introduction}

Since 1999, the scale of students recruitment in universities has been expanded, the number of college students increases rapidly, every year the number of graduates increases correspondingly, the job demands also increas. In the 21st century, along with the global financial crisis, most of the industries suffered a slow growth or even a negative growth, jobs provided by the society can far away satisfy the needs. It also made a great impact on university students' employment situation, except for some top universities in our country, students' employment rate in most universities has declined. The issue on how to strengthen the student's employment education and guidance has became an emergency in universities. In the new circumstance, most universities have provided the career planning related courses for students, with the hope to improve graduate' emploment rate. A lot of researches have been carried out on the relationship between career planning and college students' employment, but most of them are qualitative researches. This study by using the quantitative method, a statistical mode of the relationship between career planning and college students' employment rate is established, which is used for exploring the relationship between the career planning and college students' employment, and providing bases for college career planning education.

\section{Study method}

\section{A. Study object}

726 students are selected as the study object by using the completely random method, among them, boys: 517 ( $71.21 \%$ ) and girls:209 ( 28.79\% ) ; students from rural areas: 436 ( $60.06 \%$ ), students from urban areas: 290 ( 39.94\% ); students major in engineering: 421 ( 57.99\% ) (10.06 ), students major in science 73, students major in liberal arts : 62 (8.54\%) ; students major in economics and management: 170 ( 23.41\% )

\section{B. Research method}

By using the questionnaire, studying a large number of references and consulting with the teachers who have been worked for student career guidance in a long term, the "college students' career planning questionnaire" is designed . This questionnaire contains three parts: students' basic information, theory teaching and practice teaching. Both the theory teaching and practice teaching have 20 indexes which are: debating and persuading ability, oral expressing ability, organizing and 
coordinating ability, logic analysis ability, cognitive personality trait, discussion skills, dedication spirit, problem solving ability, interpersonal communication ability, self cognitive ability, learning and innovation ability, team cooperation ability, career ability, career choice, career cognition, selfawareness and the professional quality, career communication, learning objectives and career plan, each index item is used by 5-degree scoring standard, namely according to the student perception strength from strong to weak, the scores are 5, 4, 3, 2, 1.

C. Statistic analysis

By using the SPSS17.0 statistical package, the following analyses are carried out: factor analysis, correlation analysis and regression analysis. The inspection level is 0.05 .

\section{Analysis process and results}

A.Factor analysis of the questionnaire

Since there are 20 indexes in the questionnaire which are related to the career planning, the factor analysis is adopted for reducing the dimension of these indexes. Several collinearity factors are extracted.

Setting the 20 indexes as $x_{1}, x_{2}, \cdots, x_{20}$ respectively, the mean and the standard deviation as $\bar{x}_{i}$ 和 $s_{\mathrm{i}}(\mathrm{i}=1,2, \ldots, 20)$. Firstly standardizing the independent variable, then the standardized variable is obtained:

$$
x_{i}^{*}=\frac{x_{i}-\bar{x}}{s_{i}}, \quad i=1,2, \cdots, 20
$$

The model of the factor analysis is:

$$
\left\{\begin{array}{l}
x_{1}=a_{11} f_{1}+a_{12} f_{2}+\cdots+a_{1 m} f_{m}+\varepsilon_{1} \\
x_{2}=a_{21} f_{1}+a_{22} f_{2}+\cdots+a_{2 m} f_{m}+\varepsilon_{2} \\
\vdots \\
x_{20}=a_{201} f_{1}+a_{202} f_{2}+\cdots a_{20 m} f_{m}+\varepsilon_{20}
\end{array}\right.
$$

In formula (2), $f_{1}, f_{2}, \cdots, f_{m}(m \leq 20)$ are common factors; $a_{i j}(i=1,2, \cdots, 20 ; j=1,2, \cdots, m)$ named as factor loading, which reflect the correlation degree of the independent variables and common factors. $\varepsilon_{i}$ is the special factor that reflects the effects caused by other factors, mainly caused by the random error, so $\varepsilon_{i}$ usually can be ignored. The contribution made by the common factor on the of the independent variable can be reflected by the variance contribution and the variance contribution rate. The variance contribution of the common factor $f_{j}$ is:

$$
g_{j}^{2}=\sum_{i=1}^{20} a_{i j}^{2}
$$

The bigger variance contribution of the common factor the more important the common factor. Thus the variance contribution rate of the common factor is:

$$
\frac{g_{j}^{2}}{\sum_{i=1}^{20} \operatorname{var}\left(x_{i}\right)}=\frac{\sum_{i=1}^{20} a_{i j}^{2}}{20}
$$

The formula also indicates that the bigger variance contribution rate of the common factor the more important the common factor.

Before the conducting factor analysing, in order to identify wether the data is suitable for factor analysis, firstly the data should be tested by the KMO test and the Bartlett sphericity test. The results are shown in Table 1. According to Table 1, the possibility of the Bartlett sphericity test is less than the testing level 0.005 and the KMO value is close to1, which means the data is suitable for factor analysis. 


\begin{tabular}{|l|l|l|}
\hline KMO value & \multicolumn{2}{|l|}{0.745} \\
\hline Bartlett sphericity test & $\chi^{2}$ & 257.38 \\
\hline & df & 30 \\
\hline & P & 0.00 \\
\hline
\end{tabular}

Using the principle component analysis to extract factor variables, selecting those variables whose eigenvalue value is bigger than 1 . In total four factor variables are picked out, the results are shown in Table 2 . Table 2 shows that the eigenvalues of the four factors are bigger than 1 , the cumulative variance contribution rate of them is $85.39 \%$, which meets the expectation.

TABLE II.
\begin{tabular}{|c|l|l|l|}
\hline factor & VARIANCE CONTRIBUTION RATE OF THE FOUR FACTORS \\
eigenvalue & $\begin{array}{c}\text { variance } \\
\text { contribution } \\
\text { rate }(\mathbf{\%})\end{array}$ & $\begin{array}{c}\text { cumulativevariance } \\
\text { contribution rate } \\
(\mathbf{\%})\end{array}$ \\
\hline $\mathbf{1}$ & 3.23 & 43.18 & 43.18 \\
\hline $\mathbf{2}$ & 2.45 & 21.91 & 65.09 \\
\hline $\mathbf{3}$ & 1.75 & 11.54 & 76.63 \\
\hline $\mathbf{4}$ & 1.21 & 8.76 & 85.39 \\
\hline
\end{tabular}

Naming the four factor variables by using the maximum variance cross rotation, the results can be seen in Table 3. According to Table 3, the first factor variable reflects the thinking and expressing state of each individual, thus the first factor variable is the thinking and expressing ability. The second factor variable reflects the implementing and acting state then it stands for the implementing and acting ability. The third factor variable reflects the theory level of an individual, then it stands for the career theory. The fourth factor variable reflects the attitude of each individual, then it stands for the career attitude.

TABLE III. RESULTS OF MAXIMUM VARIANCE CROSS ROTATION
\begin{tabular}{|c|l|l|l|l|}
\hline index & \multicolumn{4}{|c|}{ factor } \\
\hline & 1 & 2 & 3 & 4 \\
\hline debating and persuading ability & 0.83 & & & \\
\hline oral expressing abilit & 0.75 & & & \\
\hline organizing and coordinating ability & 0.71 & & & \\
\hline logic analysis ability & 0.69 & & & \\
\hline cognitive personality trait & 0.61 & & & \\
\hline discussion skills & 0.52 & & & \\
\hline dedication spirit & & 0.77 & & \\
\hline problem solving ability & & 0.73 & & \\
\hline interpersonal communication ability & & 0.72 & & \\
\hline self cognitive ability & & 0.69 & & \\
\hline learning and innovation ability & & 0.64 & & \\
\hline team cooperation ability & & 0.50 & & \\
\hline career ability & & & 0.75 & \\
\hline career choice & & & 0.73 & \\
\hline career cognition & & & 0.72 & \\
\hline self-awareness & & & 0.71 & \\
\hline the professional quality & & & 0.62 & \\
\hline career communication & & & 0.48 & \\
\hline learning objectives & & & & 0.83 \\
\hline areer plan & & & & 0.75 \\
\hline
\end{tabular}

B. Analysis on the correlations of the career planning and graduates' employability

The correlation analysis is used for describing the degree and direction of correlation of two variables . If $\mathrm{x}$ and $\mathrm{y}$ are the two variables, the pearson product-moment correlation coefficient is:

$$
\begin{aligned}
& r_{x y}=\frac{\sum_{i=1}^{n}\left(x_{i}-\bar{x}\right)\left(y_{i}-\bar{y}\right)}{\sqrt{\sum_{i=1}^{n}\left(x_{i}-\bar{x}\right)^{2}} \sqrt{\sum_{i=1}^{n}\left(y_{i}-\bar{y}\right)^{2}}} \in[-1,1] \\
& \bar{x}=\frac{1}{n} \sum_{i=1}^{n} x_{i}, \bar{y}=\frac{1}{n} \sum_{i=1}^{n} y_{i}
\end{aligned}
$$

If the absolute value of the correlation coefficient is closer to 1 , it means the correlation degree is deeper, when the absolute value is closer to 0 , it indicates that the correlation degree is lighter. 
The results of the analyses on the correlation of each factor and the graduates employability are shown in Table 4. According to Table 4, all the four factors are related to students employability, implementating and acting ability the strongest, the following are the thinking and expressing ability, and professional theory, career attitude are the weakest.

TABLE IV. RESULTS OF THE ANALYSIS ON THE CORRELATION OF THE FOUR FACTORS AND STUDENTS EMPLOYABILITY

\begin{tabular}{|l|l|l|l|l|}
\hline & $\begin{array}{c}\text { Thinking } \\
\text { and } \\
\text { expressing } \\
\text { ability }\end{array}$ & $\begin{array}{c}\text { Implementing } \\
\text { and acting } \\
\text { ability }\end{array}$ & $\begin{array}{c}\text { Career } \\
\text { theory }\end{array}$ & $\begin{array}{c}\text { Career } \\
\text { attitude }\end{array}$ \\
\hline employability & $0.52^{*}$ & $0.58^{*}$ & $0.37^{*}$ & $0.29^{*}$ \\
\hline
\end{tabular}

note: $* \mathrm{P}<0.05$

C.The regression analysis on the career planning and graduates' employability

The correlation analysis reflects the correlation degree of those variables, while the regression analysis describes the interdependent relationship of the independent variables and dependent variables on the number bias.

According to the sample data, the regression equation can be established:

$$
\hat{Y}=b_{0}+b_{1} x_{1}+b_{2} x_{2}+\cdots+b_{m} x_{m}
$$

Setting the students employability as dependent variable and the four factors as independent variables, the multiple linear regression equation is established:

$$
\hat{Y}=5.78+0.25 x_{1}+0.44 x_{2}+0.09 x_{3}+0.07 x_{4}
$$

The prediction on the four factors and the students employability can be made through the regression equation.

\section{Conclusion}

By using the factor analysis, the four factors of the students career planning are picked out: thinking and expressing ability, implementing and acting ability, career theory and career attitude. The cumulative variance contribution of the four factors is very high which can reflect the main contents of the career planning. Through the correlation analysis, we can find that all the four factors have significant correlations with the students' employability. The the employability can be improved by strengthening the four kinds of abilities. The regression equation of the four factors and students employability is established for the prediction of students employability.

\section{References}

[1] Jifang Yang. The Empirical Research on the Relations of Career Planning Courses and Graduate Employment Soft Power[J]. College Counselors Journal , 2012,4 (2 ) :69 -73 .

[2] Qiong Ma. The Empirical Research on Influence of Career Planning on College Students' Employment Satisfaction[J]. North and South, East and West , Education Watch , 2012 ( 7 ) :150 151.

[3] Hehua Liu. Study on graduate' emploment and Entrepreneurship [J]. Taiyuan University , 2007,(6) :59-62.

[4] Jun Zhang, Wushan Yan. Study on Graduates Entrepreneurship Education[J]. Beijing Jiaotong University (Society and Science Edition ), 2008,7 (1):95-99.

[5] Lianying Huang. Study on the University Students College Career Planning Education from the Point of View of the Employment [J]. Prime years, 2011 ( 14) :130 -131 .

[6] Feng Ding. Exploration on the University students' emploment paths Based on Career Planning [J]. New campus ( learning ), 2011 ( 8 ): 24 -25 .

[7] Haijing Li, Changlin Li. Building the Career Planning System to Promote the Employment of University Students[J]. Vocational Education Forum, 2009 ( 14 ): 63 -64 .

[8] Shuoquan Pang. Analysis on the Employment of College Students in the Career Planning Perspective [J]. Jiamusi University Journal, Society and Science , 2011,29 ( 5): 129-130. 